\title{
The First Heartbeat-Origin of Cardiac Contractile Activity
}

\author{
Richard C.V. Tyser and Shankar Srinivas \\ Department of Physiology, Anatomy and Genetics, University of Oxford, Oxford OX1 3QX, United Kingdom \\ Correspondence: shankar.srinivas@dpag.ox.ac.uk
}

The amniote embryonic heart starts as a crescent of mesoderm that transitions through a midline linear heart tube in the course of developing into the four chambered heart. It is unusual in having to contract rhythmically while still undergoing extensive morphogenetic remodeling. Advances in imaging have allowed us to determine when during development this contractile activity starts. In the mouse, focal regions of contractions can be detected as early as the cardiac crescent stage. Calcium transients, required to trigger contraction, can be detected even earlier, prior to contraction. In this review, we outline what is currently known about how this early contractile function is initiated and the impact early contractile function has on cardiac development.

$\mathrm{T}_{\mathrm{h}, \mathrm{s}}^{\mathrm{s}}$ he role of the beating heart in sustaining life is so central that no other organ appears as commonly in prose and poetry, associated with not just vitality but also any number of other positive characteristics such as courage, honesty, perseverance, loyalty, and, of course, love. The rhythmic beating of the heart is so constant and all-pervasive during our life that we often take it for granted. In this review, we discuss what we currently know about when this rhythmic activity first starts.

The heart starts to develop in the mouse at approximately embryonic day 8.0 and in the human at around 16 days after fertilization. It is arguably the first organ to form and function during embryogenesis as it shows contractile activity already at these earliest stages (Fig. 1). In this review, we use "cardiac function" to mean the ability of cardiomyocytes to contract to produce force. This contractile function is critical in supplying the rapidly growing postimplantation embryo with sufficient oxygen and nutrients to develop properly. Because of the fundamental role of the heart, early perturbations in its development frequently result in embryonic lethality (Copp 1995). Indeed, congenital heart disease accounts for $10 \%$ of all spontaneous abortions, and heart defects are present in $1 \%$ of all live births (Triedman and Newburger 2016).

The embryonic heart is composed of maturing cardiomyocytes and cardiac progenitors that have yet to differentiate (Meilhac and Buckingham 2018). It also undergoes significant morphological changes, transitioning from a crescent into the linear heart tube (LHT). Recent live imaging experiments have reported two waves of development during this period, with an initial wave of differentiation followed by a second in which morphological changes occur (Ivanovitch et al. 2017). Among organs, the heart is unusual in having to contract rhythmically while still undergoing extensive remodel-

Editors: Benoit G. Bruneau and Paul R. Riley

Additional Perspectives on Heart Development and Disease available at www.cshperspectives.org

Copyright (C) 2020 Cold Spring Harbor Laboratory Press; all rights reserved; doi: 10.1101/cshperspect.a037135

Cite this article as Cold Spring Harb Perspect Biol 2020;12:a037135 
R.C.V. Tyser and S. Srinivas

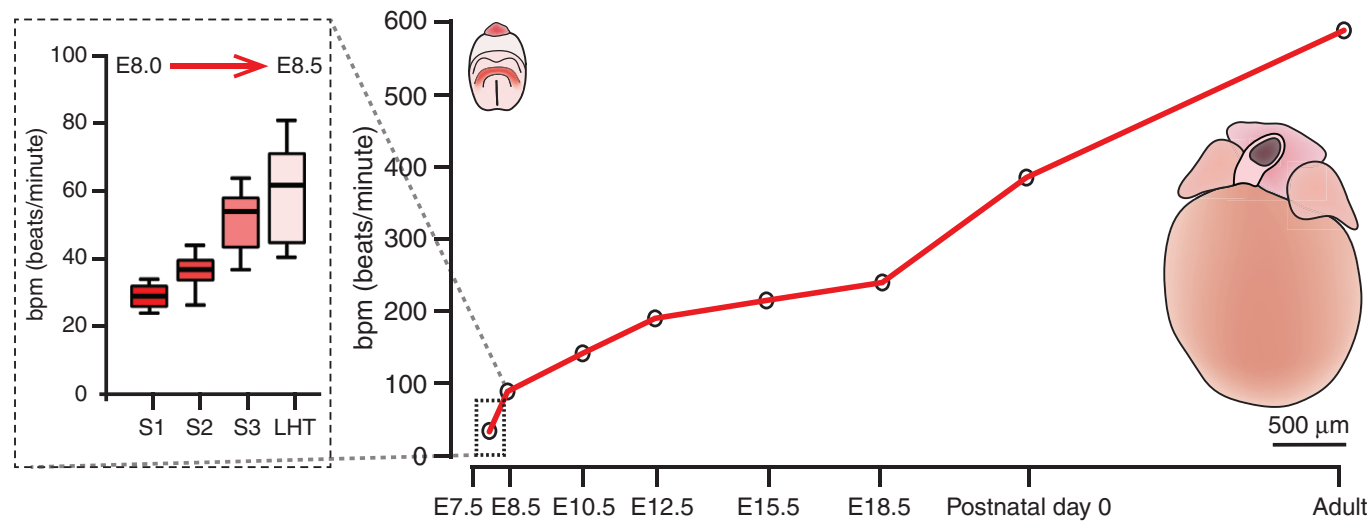

Figure 1. Increase in beat rate during the course of heart development. During mouse development, cardiac contractile activity starts at approximately embryonic day 8.0 at roughly 30 beats per minute (bpm) and increases in the adult mouse to $600 \mathrm{bpm}$. The dotted box shows the rapid increase in rate of contraction during the onset of cardiac function from cardiac crescent stages 1 through to the linear heart tube, roughly a 12-hour period from approximately E8.0 to E8.5. The images show, to scale, an embryo at E8.0 (at left, cardiac crescent in red) and an isolated adult mouse heart (at right). (LHT) Linear heart tube.

ing. The coordinated changes in morphology, physiology, and cellular maturation that occur during the onset of cardiac function highlights how the development of form and function in the embryonic heart are inextricably linked. This raises important questions regarding when contractile activity is first initiated during development, the extent to which this influences the formation of cardiomyocytes, and its impact on subsequent cardiac morphogenesis. This is especially important as the forces exerted by cardiac contractions have been shown in several models to be required for proper heart development (Granados-Riveron and Brook 2012) and for modulating gene expression (Miyasaka et al. 2011) at later developmental stages.

Cardiac function is crucial not only for heart development but also for the development of the whole embryo, with knockout of key components of cardiac function leading to embryonic lethality around E9.5-E10.5 in the mouse (Table 1). Cardiac contraction is vital in providing nutrients to the developing embryo as well as influencing mechanosensory and calcium signaling. This leads to regulated gene expression and differentiation of cardiomyocytes, as well as other embryonic cell types such as endothelial and hematopoietic progenitors. In the LHT, contractile activity and circulation generate hemodynamic forces and wall sheer stress that guide the morphological changes that occur during cardiac looping (Hove et al. 2003). Hemodynamic forces generated by cardiac contraction are also necessary and sufficient to induce vessel remodeling in the mammalian yolk sac (Lucitti et al. 2007). It is also required for the distribution of hematopoietic progenitors throughout the fetus (Lux et al. 2007) and regulates their differentiation (North et al. 2009).

In this review, we describe what is known about when and how the heart first establishes coordinated contractile activity. We start with a brief historic overview of pioneering studies in this area. This is followed by a description of the cellular machinery that generates the force required for contraction to occur and the mechanisms that ensure these forces are coordinated both within the cell and across the field of contractile cells. We conclude with a discussion of emerging approaches for disentangling the many questions that remain regarding how the heart first starts to beat.

\section{ONSET OF CARDIAC FUNCTION}

Fascination with when the heart starts to beat has existed for centuries, with the recurring theme that as technology has advanced, the pre- 
Table 1. The role of ECC proteins during embryonic heart development

\begin{tabular}{lc}
\hline Protein (gene) & Cardiac phenotype \\
\hline NCX1 (Slc8a1) & Lethality E9 to E10; thin myocardium with reduced cardiomyocytes; no heartbeat observed \\
& (Wakimoto et al. 2000) \\
& Lethality E9.0 to E9.5; underdeveloped heart with dilated pericardium; contractile although \\
& significantly slower than wild-type (WT) littermates; mutant and WT hearts indistinguishable \\
& at E8.5 (Cho et al. 2000) \\
& Lethality E11.5 to E13.5; lack of a spontaneous beating heart and organized myofibrils (Koushik \\
& et al. 2001) \\
& Lethality prior to E14.5; normal development until E12.5, contractile rate the same as WT \\
Cav1.2 (Cacna1c) & littermates (Seisenberger et al. 2000) \\
Vav1.3 (Cacna1d) & Viable embryos; pronounced bradycardia and arrhythmias at rest in the adult; altered sinoatrial \\
& pacemaker activity (Platzer et al. 2000) \\
RyR2 (Ryr2) & Lethality E10.5 to E11.5; rhythmic contractions at E9.5, although irregularly arranged \\
& myocardium; no heartbeat at E10.5, anatomically similar to E9.5 (Takeshima et al. 1998) \\
SERCA2a (Atp2a2) & No mutant embryos detected with germline deletion (Periasamy et al. 1999); conditional \\
& myocardial deletion led to lethality at E11.5; circulation and heartbeat observed until E10.5 \\
& (Andersson et al. 2009) \\
Lethality E10.5 to E11.5; some uncoordinated beating at E10.5, however, none observed at E11.5; \\
Neduced ventricular chamber size, trabeculation, and cardiomyocytes (Papadatos et al. 2002)
\end{tabular}

Summary of studies in which proteins required for excitation-contraction coupling (ECC) cardiac physiology and $\mathrm{Ca}^{2+}$ handling have been deleted in mice. All deletions are germline unless otherwise stated.

cise stage at which it has been reported to start beating has become earlier and earlier. Contractile activity has been observed directly through the microscope (Sabin 1920; Nishii et al. 2006; Chen et al. 2015) or, more recently, inferred by using organic dyes to visualize the $\mathrm{Ca}^{2+}$ oscillations and voltage action potentials that control contraction (Kamino 1991). We have even been able to use atomic force microscopy to detect contractile activity at a stage when it is not visually detectible with an optical microscope (Chen et al. 2015).

In addition to detection technology, refinements in staging the developing heart have allowed the onset of cardiac function to be more precisely defined (see below and Fig. 2). Older studies have used "embryonic day" or the number of somite pairs to stage heart development. Although these are useful for more general staging of the embryo, they do not offer the granularity required to accurately stage the embryonic heart during a time of rapid morphological change from the early cardiac crescent to LHT. Furthermore, somite number does not consistently correlate to the overall embryonic stage (Kaufman and Navaratnam 1981) or development of the heart because of normal variation in the rate of development of different structures in the embryo and differences in genetic background. This can lead to ambiguities because, for example, the three-somite stage may include embryos that range from the cardiac crescent to early LHT stages. To more accurately assess and describe changes in the forming heart, we and others have developed staging systems specific to the early heart (Tyser et al. 2016; Ivanovitch et al. 2017; Le Garrec et al. 2017). Based on morphological criteria, we divide the cardiac crescent into four distinct stages (stages 0 through 3 ) leading to the early LHT (Fig. 2).

Modern studies of the embryonic onset of cardiac function were first undertaken in 1920 by Florence Sabin, a pioneer of women in science, being the first woman to hold a full pro- 


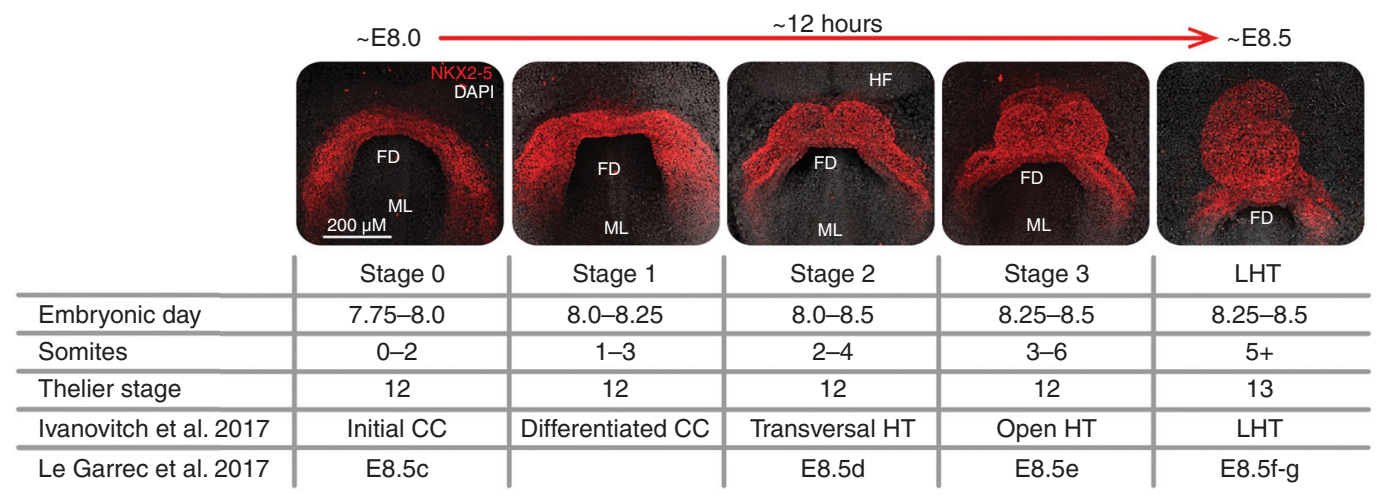

Figure 2. Staging system for cardiac development. We developed a numerical staging system to describe different phases of early cardiac development in a fine-grained manner. Stages 0 to 2 correspond to progressively more developed cardiac crescents (CC), whereas stage 3 represents a transition toward the linear heart tube (LHT) stage. Images are maximum-intensity projections of whole mount immunofluorescence showing the expression of NKX2-5, a marker of cardiac progenitors, highlighting changes in cardiac morphology during these stages. The table shows other staging systems for comparison, including two other recent systems specific to the heart. (FD) Foregut diverticulum, (ML) midline, (HF) headfold.

fessorship at Johns Hopkins University and the first woman elected to the American National Academy of Science in 1925. In her study published in 1920, Sabin used the chick embryo to investigate the origin of blood vessels and blood corpuscles (Sabin 1920). She cultured embryos hanging from a glass coverslip for up to 5 hours and observed them using a brightfield microscope. Although her primary focus was not on the heart, in these studies she first reported the onset of beating in the chick embryo at the 10somite stage ( $\sim \mathrm{HH} 10)$ at a single location along the right-hand margin of the medial primitive ventricle of an LHT that had already started the process of looping. She described how this initial slow rhythmic beating would spread from the caudal to rostral end of the LHT.

The first dedicated study into the initiation of cardiac contraction was conducted by Pattern and Kramer in 1933, again in the chick embryo. They reported that contractions started in the primitive ventricle of the LHT around the nineor 10-somite stage (Patten and Kramer 1933). They differed from Sabin in that they observed several locations with "local twitching" but always within the right wall of the primitive ventricle as Sabin had found. When first detected, these twitches were not rhythmic, but soon became coordinated. Pattern and Kramer conclud- ed that their findings differed from that of Sabin because they were able to detect contractions earlier, because of methodological advances and their ability to use enlarged film tracings to pick up less evident changes. They went on to describe how the contractile regions on the right side of the primitive ventricle become coordinated before the "restless" left side begins to contract synchronously with the right. At this point, the entire primitive ventricle contracts as one, but subsequently over the course of 1-2 hours the contractile activity changes to sweep through the ventricle in a caudal to rostral direction.

The first studies in mammals were conducted by Goss in 1938 using rat embryos. He reported that contractile activity began at E9.5 (equivalent approximately to E8.5 in mice) in the lateral ventricular myocardium of the left LHT. These first contractions had a regular rhythm and a rate of 37 to 42 beats per minute (bpm) (Goss 1938). He further described pacemaker-like activity in regions on either side of the embryonic midline, suggesting that in contrast to the chick, contractile function in rats commenced prior to the formation of the LHT at around the two- to three-somite stage (Goss 1952).

These earlier studies relied on the use of brightfield microscopy to determine the onset 
of contraction. However, as new fluorescence imaging technologies developed, voltage and $\mathrm{Ca}^{2+}$-sensitive dyes were used to measure action potentials and $\mathrm{Ca}^{2+}$ transients in early embryonic hearts. Kamino and colleagues showed, using voltage-sensitive dyes, that spontaneous electrical activity could be observed in the chick cardiac primordium at the six- and early sevensomite stage and in rat at the three-somite stage (Kamino 1991). More recently, $\mathrm{Ca}^{2+}$ transients were reported in the cardiac crescent of rat embryos (Kobayashi et al. 2011).

As the mouse became the established model for studying mammalian development, staging systems based on the number of somite pairs were created to compare development of different species (Kaufman and Navaratnam 1981). Using this staging approach, the onset of cardiac contraction in the mouse was placed at the threeto four-somite stage, corresponding roughly to the LHT at E8.5 (Navaratnam et al. 1986). Later studies in mouse embryos reported that contractile activity could be first detected in the cardiac crescent at the three-somite stage initiating at 30 bpm (Nishii et al. 2006). This study showed that contractions initiated on either the left or right side and that independent regions had different beating rates.
Most recently, we have shown that contraction initiates earlier, in the lateral regions of the early cardiac crescent that we term "stage 1" corresponding with the one- to three-somite stage embryo (Fig. 2). We do not observe contractions or sarcomeric banding at earlier stages (stage 0 and earlier), consistent with the notion that assembly of the contractile machinery into sarcomeres is required to generate sufficient spatial displacement to be detected optically. When first detected, these contractions are $\sim 30 \mathrm{bpm}$ but increase to $>60 \mathrm{bpm}$ with formation of the LHT (Tyser et al. 2016). This indicates that cardiomyocytes start contracting at the very earliest stages of heart development, essentially as soon as they are formed and assemble mature sarcomeres (Fig. 3).

Coordinated $\mathrm{Ca}^{2+}$ transients are also required for rhythmic contraction. At stage 0 , prior to the onset of contraction, we detected spontaneous asynchronous calcium oscillations (SACOs) in immature cardiomyocytes (discussed later in this review), suggesting that as cells mature, the molecular machinery for $\mathrm{Ca}^{2+}$ handling is put in place slightly before the contractile machinery is assembled into sarcomeres. Although we cannot exclude the possibility that contractile activity exists earlier than stage 1 , it is

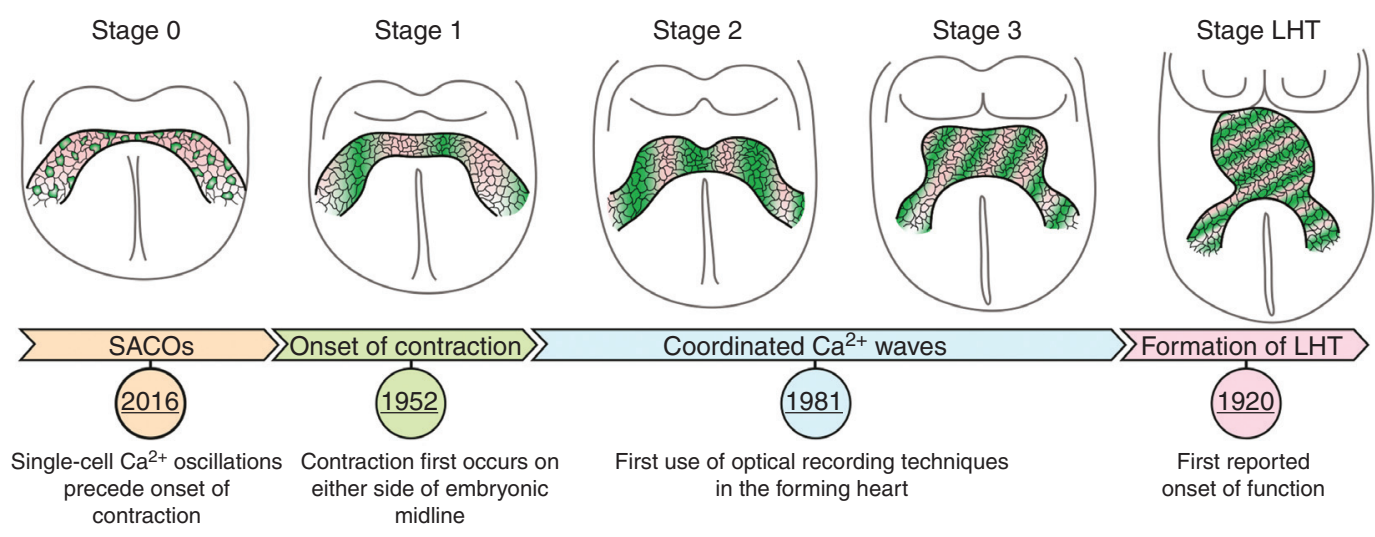

Figure 3. Changes in $\mathrm{Ca}^{2+}$ dynamics during the onset of cardiac function. Schematic of the changes that occur during development of the cardiac crescent. Green shading represents changes in the cytoplasmic level of $\mathrm{Ca}^{2+}$. At stage 0 , prior to the onset of function, spontaneous asynchronous calcium oscillations (SACOs) are observed in single cells. At stage 1, contractions can first be observed with $\mathrm{Ca}^{2+}$ transients propagating through the cardiac crescent in a lateral orientation. At later stages, the rate of $\mathrm{Ca}^{2+}$ transient propagation continues to increase in line with the rate of contraction. At the linear heart tube (LHT) stage, $\mathrm{Ca}^{2+}$ transients begin to propagate in a more caudal to rostral direction. 
R.C.V. Tyser and S. Srinivas

unlikely, given that cardiac progenitors lack the sarcomeric assemblies required for contraction and do not have coordinated $\mathrm{Ca}^{2+}$ activity.

\section{MOLECULAR UNDERPINNING OF CARDIAC FUNCTION}

Cardiomyocytes have a highly defined structure that allows them to respond to rhythmic electrical excitation to generate the force required to circulate blood around the body. Immature cardiomyocytes/progenitors must develop both the apparatus needed to generate physical contraction and the ability to regulate contraction in a synchronized manner. These two requirements are met, respectively, by the formation of sarcomeres and the coordinated activity of channels, pumps, and exchangers to modulate cytosolic $\mathrm{Ca}^{2+}$ levels.

The contractile apparatus of cardiomyocytes, the myofibrils, are long structures composed of bundles of myosin, actin, and titin, making up the thick, thin, and elastic filaments, respectively (Clark et al. 2002; Ehler 2016). These filaments are arranged in a repeating manner along the length of the myofibril in units called sarcomeres. The alignment of sarcomeres across myofibrils is what gives cardiomyocytes their characteristic striated appearance. Contraction of myofibrils relies on the binding of $\mathrm{Ca}^{2+}$ to the troponin complex, leading to a conformational change that causes myosin heads to flex and slide along the actin filaments, shortening sarcomere length and resulting in the generation of contractile force (Metzger and Westfall 2004). For contraction to occur in nascent cardiomyocytes, this highly organized contractile machinery needs to first form. Analyses over the course of cardiac crescent to LHT formation have shown that contractile proteins required for function are expressed in a region- and time-dependent manner (Tyser et al.2016). One of the earliest contractile proteins to be expressed is cardiac troponin T, which is expressed throughout the cardiac crescent prior to the onset of function (Ivanovitch et al. 2017). In contrast, other sarcomeric proteins such as sarcomeric- $\alpha$ actinin and myomesin are initially only detected in the more lateral regions of the cardiac crescent prior to the onset of contraction, in the regions in which contractile function is first initiated (Tyser et al. 2016). These regional differences in the expression of contractile proteins could be the result of a mediolateral gradient of maturation within the cardiac crescent, with more lateral cells being the first to mature sufficiently to assemble functional sarcomeres and therefore being the first to display contractile function. More detailed fate mapping of the cardiac mesoderm, which gives rise to the crescent, will need to be conducted to test this possibility.

Expression of contractile proteins is not in itself sufficient for contractile activity-they need to be assembled into sarcomeres. Prior to contraction, a number of sarcomeric proteins can be observed in the cardiac crescent, but not in the banded pattern characteristic of sarcomeres. As the crescent develops rapidly over the time course of 1-2 hours, one can see the emergence of sarcomere banding in a small number of cells in the lateral regions of the stage 1 crescent, highlighting the formation of functional sarcomeres and corresponding with the onset of function (Tyser et al. 2016). Subsequently, as cardiac development progresses through stages 2 and 3, the expression of contractile proteins continues to increase and sarcomeric banding rapidly spreads across the crescent, resulting in increased contraction.

In addition to sarcomeric organization, the other aspect crucial to cardiac function is the ability to modulate the cytoplasmic level of $\mathrm{Ca}^{2+}$, which is what actually triggers contraction. When contractile components such as cardiac troponin $\mathrm{T}$ (encoded by Tnnt2) are knocked out, the onset of contraction is prevented but $\mathrm{Ca}^{2+}$ transients still persist, the heart develops normally until E8.75, and the embryo dies between E10.5 and E11.5 (Nishii et al. 2008). In contrast, when the $\mathrm{Na}^{+} / \mathrm{Ca}^{2+}$ exchanger, a key complex required for $\mathrm{Ca}^{2+}$ homeostasis, is knocked out, both $\mathrm{Ca}^{2+}$ transients and contraction fail, resulting in embryonic lethality as early as E9.5 (Wakimoto et al. 2000). This highlights that, for the onset of cardiac function, it is crucial that both the contractile apparatus and the ability to dynamically regulate cytosolic $\mathrm{Ca}^{2+}$ are present. 


\section{CHANGING CARDIOMYOCYTE PHYSIOLOGY IN THE DEVELOPING HEART}

For rhythmic contractions to occur, the intracellular concentration of $\mathrm{Ca}^{2+}$ must increase and decrease in a periodic manner, to regulate myosin-actin interaction. For the onset of cardiac function, cardiac progenitors, therefore, must have the ability to dynamically regulate the concentration of cytosolic $\mathrm{Ca}^{2+}$. In adult cardiomyocytes, rapid changes in concentration of intracellular $\mathrm{Ca}^{2+}$ are coupled to coordinated electrical excitation in a process termed excitation contraction coupling (ECC), predominant- ly relying on $\mathrm{Ca}^{2+}$ release from the sarcoplasmic reticulum (SR) (Fig. 4; Bers 2002).

Although ECC has been well characterized in mature cardiomyocytes, it is less well defined in embryonic cardiomyocytes during the onset of function. Targeted disruption of genes encoding ECC proteins in mice has shown that the early contractile activity of immature cardiomyocytes evidently does not require ECC (Table 1). In the majority of these transgenic models, the immature heart remained contractile until $\sim$ E11.5, highlighting physiological differences in the mechanism by which cytosolic $\mathrm{Ca}^{2+}$ levels are regulated in the adult versus embryonic

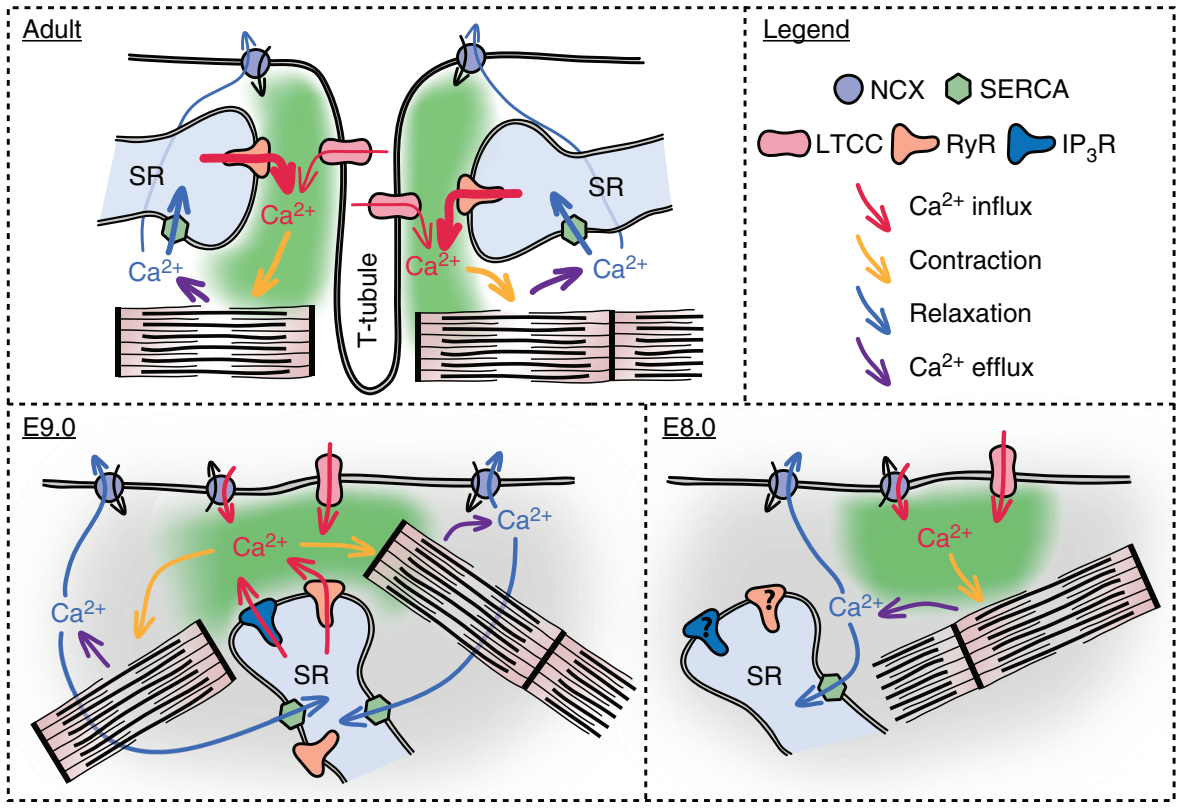

Figure 4. The mechanism of $\mathrm{Ca}^{2+}$ regulation is significantly different in adult compared to embryonic cardiomyocytes. In the adult cardiomyocyte, contraction occurs via excitation-contraction coupling (ECC) in which an action potential triggers the opening of L-type $\mathrm{Ca}^{2+}$ channels (LTCCs) causing $\mathrm{Ca}^{2+}$ influx, which leads to the release of $\mathrm{Ca}^{2+}$ from the sarcoplasmic reticulum (SR) via ryanodine receptors (RyRs). The increase in cytoplasmic $\mathrm{Ca}^{2+}$ leads to contraction of myofibrils. For relaxation to occur, the $\mathrm{Ca}^{2+}$ is removed from the cytoplasm; the majority of $\mathrm{Ca}^{2+}$ is pumped back into the SR via SERCA while some is removed by the $\mathrm{Na}^{+} / \mathrm{Ca}^{2+}$ exchanger (NCX). In E9.0 cardiomyocytes, $\mathrm{Ca}^{2+}$ transients are driven by the spontaneous release of $\mathrm{Ca}^{2+}$ from the SR via RyRs and inositol 3-phosphate receptors ( $\mathrm{IP}_{3} \mathrm{Rs}$ ). This leads to $\mathrm{Ca}^{2+}$ efflux via NCX, which, because of its electrogenic properties, triggers membrane depolarization leading to the opening of LTCCs and further $\mathrm{Ca}^{2+}$ influx. It is also reported that NCX has a role in $\mathrm{Ca}^{2+}$ influx because of its ability to work in both forward $\left(\mathrm{Ca}^{2+}\right.$ efflux) and reverse $\left(\mathrm{Ca}^{2+}\right.$ influx) modes. During the onset of function (E8.0), both NCX and LTCCs are required for the generation of $\mathrm{Ca}^{2+}$ transients. However, current evidence suggests that both RyRs and $\mathrm{IP}_{3} \mathrm{Rs}$ are not involved at this stage, with plasmalemmal $\mathrm{Ca}^{2+}$ flux being the main mechanism for changing cytoplasmic $\mathrm{Ca}^{2+}$ levels. 
cardiomyocyte. These differences are also manifested in the resting membrane potential of adult cardiomyocytes $(-75 \mathrm{mV})$ compared to E8.5 immature embryonic cardiomyocytes $(-33.2 \mathrm{mV})$ (Sasse et al. 2007).

Historically, two opposing mechanisms have been proposed for $\mathrm{Ca}^{2+}$ handling in immature cardiomyocytes. Initially, it was suggested that increases in the concentration of cytosolic $\mathrm{Ca}^{2+}$ were solely the result of plasmalemmal $\mathrm{Ca}^{2}$ ${ }^{+}$entry with little or no contribution from SR stores (Nakanishi et al. 1988; Takeshima et al. 1998). However, later studies in embryonic cardiomyocytes showed that $\mathrm{Ca}^{2+}$ transients can also be driven by SR Ca ${ }^{2+}$ release (ViatchenkoKarpinski et al. 2002; Méry et al. 2005). Most recently, studies have shown that a combination of both plasmalemmal $\mathrm{Ca}^{2+}$ influx and spontaneous SR $\mathrm{Ca}^{2+}$ release are required for function in early embryonic cardiomyocytes (Sasse et al. 2007; Rapila et al. 2008; Karppinen et al. 2014).

The earliest detailed electrophysiological analysis of immature cardiomyocytes used cardiomyocytes cultured for between 12 to 70 hours after being isolated from embryonic hearts between E8.5 and E9.5, roughly 12 hours after the in vivo onset of function (Reppel et al. 2007; Rapila et al. 2008; Liang et al. 2010). Using such a system, the mechanism by which contraction is regulated was shown to originate in the spontaneous release of $\mathrm{Ca}^{2+}$ from SR stores via ryanodine (RyRs) and inositol 3-phosphate receptors $\left(\mathrm{IP}_{3} \mathrm{Rs}\right)$ (Fig. 4; Sasse et al. 2007; Rapila et al. 2008). This spontaneous release of $\mathrm{Ca}^{2+}$ elevates the concentration of cytosolic $\mathrm{Ca}^{2+}$ leading to the removal of $\mathrm{Ca}^{2+}$ via the $\mathrm{Na}^{+} / \mathrm{Ca}^{2+} \mathrm{ex}-$ changer. The $\mathrm{Na}^{+} / \mathrm{Ca}^{2+}$ exchanger is electrogenic and its removal of $\mathrm{Ca}^{2+}$ creates a small inward current, which leads to membrane potential depolarization and the activation of voltage-gated $\mathrm{Na}^{+}$and $\mathrm{Ca}^{2+}$ channels, thereby generating an action potential. Whereas early embryonic cardiomyocytes are thought to be voltage-independent $\mathrm{Ca}^{2+}$ oscillators, the generation of such action potentials is thought to provide a mechanism for the synchronization of electrical and mechanical signals (Sasse et al. 2007; Rapila et al. 2008). Studies on early immature cardiomyocytes at the same stage have also demon- strated that not only is the $\mathrm{Na}^{+} / \mathrm{Ca}^{2+}$ exchanger important for the efflux of $\mathrm{Ca}^{2+}$ following cytosolic increases in concentration but it can also play a role in $\mathrm{Ca}^{2+}$ influx at more positive membrane potentials, thereby having a fundamental role in $\mathrm{Ca}^{2+}$ homeostasis and the onset of cardiac function, especially in light of the more depolarized resting membrane potential at these stages (Linask et al. 2001; Reppel et al. 2007).

More recently, we have examined the molecular basis for $\mathrm{Ca}^{2+}$ regulation in the intact cardiac crescent during the onset of function and subsequent maturation of early cardiac progenitors, using ex vivo whole embryo $\mathrm{Ca}^{2+}$ imaging. We find a shift between mechanisms through which $\mathrm{Ca}^{2+}$ transients are generated, with limited contribution from the SR (Fig. 4). Early function in the stages 1 to 2 cardiac crescent can be inhibited by blocking both the $\mathrm{Na}^{+} / \mathrm{Ca}^{2+}$ exchanger and L-type channels. However, as the crescent matures toward the LHT, blocking the $\mathrm{Na}^{+} / \mathrm{Ca}^{2+}$ exchanger no longer has an inhibitory effect on the generation of $\mathrm{Ca}^{2+}$ transients while blocking the L-type channel continues to do so. Blocking $\mathrm{Ca}^{2+}$ release from SR stores by inhibiting RyRs and $\mathrm{IP}_{3} \mathrm{Rs}$ did not have an effect on $\mathrm{Ca}^{2+}$ transient generation at early crescent stages, indicative of a limited role for the SR at this stage. Inhibition of these receptors, however, prevents contraction shortly thereafter (at the looping LHT stage at $\sim$ E8.5), consistent with previous reports that $\mathrm{Ca}^{2+}$ transients in the E8.5 heart originate from SR through RyRand $\mathrm{IP}_{3} \mathrm{R}$-mediated $\mathrm{Ca}^{2+}$ release (Sasse et al. 2007; Rapila et al. 2008). The absence of a role for the SR in generating $\mathrm{Ca}^{2+}$ transients in the cardiac crescent may be because the SR is functionally immature in these early cardiomyocytes, potentially because of an absence of functional RyR and $\mathrm{IP}_{3} \mathrm{Rs}$. Alternatively, this early stage might represent a period of $\mathrm{SR} \mathrm{Ca}^{2+}$ filling, during which the concentration of $\mathrm{SR} \mathrm{Ca}^{2+}$ is increasing but is not yet at a level where spontaneous $\mathrm{Ca}^{2+}$ release occurs. Detailed analyses of $\mathrm{SR} \mathrm{Ca}^{2+}$ concentration in isolated nascent cardiomyocytes cells is needed to clarify between these possibilities. Together, these data suggest that during the onset of cardiac function, the initial $\mathrm{Ca}^{2+}$ transients are derived from sarco- 
lemmal $\mathrm{Ca}^{2+}$ flux and that the SR is still maturing until LHT stages whereupon SR-derived $\mathrm{Ca}^{2}$ ${ }^{+}$oscillations predominate. Further electrophysiological characterization, ideally on cardiomyocytes within the context of the intact crescent, is required to verify this shift in cellular $\mathrm{Ca}^{2+}$-handling mechanisms.

\section{SPONTANEOUS ASYNCHRONOUS $\mathrm{Ca}^{2+}$ OSCILLATIONS PRECEDE OVERT CONTRACTILE ACTIVITY}

Synchronized $\mathrm{Ca}^{2+}$ transients can be detected in the early cardiac crescent at stage 1, often before the onset of contractile activity. However, even before the appearance of these synchronized $\mathrm{Ca}^{2+}$ transients, nascent cardiomyocytes in the early stage 0 cardiac crescent display SACOs in the absence of contractile activity (Tyser et al. 2016). SACOs show a range of $\mathrm{Ca}^{2+}$ dynamics with variable frequencies and durations. The rate of these oscillations range from two to less than one oscillation per minute, significantly slower than the rate at which contractile activity initiates (30 bpm). SACOs could be inhibited by blocking the $\mathrm{Na}^{+} / \mathrm{Ca}^{2+}$ exchanger, which in adult cardiomyocytes is primarily responsible for $\mathrm{Ca}^{2+}$ efflux, suggesting as previously reported that the $\mathrm{Na}^{+} / \mathrm{Ca}^{2+}$ exchanger could be responsible for oscillations in immature cardiomyocytes, having a role in both $\mathrm{Ca}^{2+}$ influx and efflux (Reppel et al. 2007). Interestingly inhibition of the voltage-gated L-type calcium channel did not inhibit SACOs, suggesting these oscillations may be generated in a voltage-independent manner. Whether the SR has a role in generating these oscillations is unclear, although it has been shown that inhibition of RyRs and $\mathrm{IP}_{3}$ Rs did not prevent SACOs in the forming crescent, suggesting that SACOs are generated by sarcolemmal rather than SR-generated $\mathrm{Ca}^{2+}$ flux.

The observation that SACOs at stage 0 preceded the onset of coordinated $\mathrm{Ca}^{2+}$ transients in the stage 1 cardiac crescent, just 1-2 hours later, raises several fundamental questions regarding how synchronization occurs, when SACOs first originate in cardiac progenitors and whether these early SACOS play any direct role in cardiomyocyte development. In this context, it is interesting to note that $\mathrm{Ca}^{2+}$ signaling within early cardiac progenitors appears to be important in promoting maturation into cardiomyocytes. In addition to its role in contraction, $\mathrm{Ca}^{2+}$ is a crucial second messenger involved in a number of different signaling pathways (Pucéat and Jaconi 2005). Transgenic mice in which SR Ca ${ }^{2+}$ homeostasis was dysregulated show embryonic malformations, impaired $\mathrm{Ca}^{2+}$ signaling, and compromised $\mathrm{Ca}^{2+}$-dependent transcription (Mesaeli et al. 1999). The release of $\mathrm{Ca}^{2+}$ from SR stores in E9.0 cardiomyocytes leads to changes in $\mathrm{Ca}^{2+}$-dependent signaling pathways, alters localization of histone deacetylases, and regulates expression of cardiac developmental genes (Karppinen et al. 2018). In immature cardiomyocytes at E8.0, $\mathrm{Na}^{+} / \mathrm{Ca}^{2+}$ exchanger function is essential not only for generating early $\mathrm{Ca}^{2+}$ transients but also for cardiomyocyte differentiation and correct phosphorylation of CamKinase (Tyser et al. 2016), which is known to regulate gene expression by phosphorylating various transcription factors, thereby linking cardiac cellular physiology and gene transcription (Molkentin 2006). Misregulation of this process can have profound consequences. Abnormal $\mathrm{Ca}^{2+}$ signaling in adult cardiomyocytes has been implicated in some types of pathological hypertrophy associated with heart failure. This is understood to happen as a result of the abnormal reactivation of genes normally only expressed during development, such as $M e f 2 c$, $N k \times 2-5$, and $M y h 7$, that are required for cardiomyocyte differentiation.

\section{FUTURE PROSPECTS}

Investigating the onset of cardiac function in vivo is technically challenging because of the size and accessibility of mammalian embryos. Embryonic stem cells (ESCs) have emerged as a useful in vitro model for studying differentiation and cellular function. Since the development of induced pluripotent stem cells (iPSCs), they, along with ESC-derived cardiomyocytes, have become widely used as models to investigate cardiomyocyte development. Early studies using mouse (mESCs) have shown that they can differentiate into functional cardiomyocytes in 
vitro and recapitulate the pre- and postgastrulation cardiogenic events that occur in vivo (Mercola et al. 2011; Mummery et al. 2012; Burridge et al. 2012). Although these models lack the morphological cues of in vivo developing embryos at the transcriptional and phenotypic level, they are similar, expressing physiologically relevant proteins in a stage-specific manner. They also provide a practical means of studying initiation of cardiac function during human development, which would otherwise be intractable given the various challenges associated with human embryo research. In terms of cardiac function, mESC-derived cardiomyocytes start contracting at $\sim 30 \mathrm{bpm}$, a rate similar to the first contractions detected in intact embryos (Tyser et al. 2016). This suggests that there is an intrinsic rate of $\mathrm{Ca}^{2+}$ handling during the transition of cardiac progenitors into functional immature cardiomyocytes and that ESC-based models faithfully capture events occurring in the embryo.

One of the most striking biological phenomena during the initiation of cardiac function is the observation of SACOs prior to coordinated $\mathrm{Ca}^{2+}$ transients and contractile activity, raising questions regarding their onset, synchronization, and biological context. To understand these questions, it is important to use live imaging of embryo development using novel techniques such as light sheet microscopy (McDole et al. 2018) in combination with live reporters. Genetically encoded $\mathrm{Ca}^{2+}$ reporters have been widely used in the field of neuroscience to investigate neural activity within distinct cell populations (Chen et al. 2013). Applying these tools to heart development will allow $\mathrm{Ca}^{2+}$ dynamics to be visualized and monitored in intact embryos during formation of the cardiac crescent, something not possible with traditional dyes, and allow us to address how SACOs become coordinated to produce synchronized $\mathrm{Ca}^{2+}$ transients.

Over the last 5 years, there has been an explosion in the use of single-cell sequencing to explore cellular heterogeneity within tissues and gene expression of individual cells in different tissue types. Recent papers have applied this technique to the developing embryo, covering stages in which the onset of function occurs (de Soysa et al. 2019; Pijuan-Sala et al. 2019). Using these data sets along with bioinformatic techniques, it should be possible to determine the order in which genes required for sarcomere formation or SACO synchronization are expressed during early cardiac development. Any in silico analyses will need to be validated using fundamental physiological approaches to piece together how cardiac function is initiated. Such insights will contribute to a deeper understanding of how cardiac contractile function is triggered and facilitates efforts in regenerative medicine focused on promoting functional integration of de novo-generated cardiomyocytes into a damaged heart.

\section{ACKNOWLEDGMENTS}

R.C.V.T. is funded through a British Heart Foundation Immediate Fellowship FS/18/24/ 33424. The work in the S.S. group is funded through a Wellcome Senior Investigator Award 103788/Z/14/Z and Wellcome Strategic Awards $105031 / \mathrm{C} / 14 / \mathrm{Z}$ and $108438 / \mathrm{Z} / 15 / \mathrm{Z}$.

\section{REFERENCES}

Andersson KB, Finsen AV, Sjåland C, Winer LH, Sjaastad I, Ødegaard A, Louch WE, Wang Y, Chen J, Chien KR, et al. 2009. Mice carrying a conditional Serca $2^{\text {flox }}$ allele for the generation of $\mathrm{Ca}^{2+}$ handling-deficient mouse models. Cell Calcium 46: 219-225. doi:10.1016/j.ceca.2009.07.004

Bers DM. 2002. Cardiac excitation-contraction coupling. Nature 415: 198-205. doi:10.1038/415198a

Burridge PW, Keller G, Gold JD, Wu JC. 2012. Production of de novo cardiomyocytes: human pluripotent stem cell differentiation and direct reprogramming. Cell Stem Cell 10: 16-28. doi:10.1016/j.stem.2011.12.013

Chen TW, Wardill TJ, Sun Y, Pulver SR, Renninger SL, Baohan A, Schreiter ER, Kerr RA, Orger MB, Jayaraman V, et al. 2013. Ultrasensitive fluorescent proteins for imaging neuronal activity. Nature 499: 295-300. doi:10.1038/na ture 12354

Chen CM, Miranda AMA, Bub G, Srinivas S. 2015. Detecting cardiac contractile activity in the early mouse embryo using multiple modalities. Front Physiol 5: 508. doi:10 .3389/fphys.2014.00508

Cho CH, Kim SS, Jeong MJ, Lee CO, Shin HS. 2000. The $\mathrm{Na}^{+}-\mathrm{Ca}^{2+}$ exchanger is essential for embryonic heart development in mice. Mol Cells 10: 712-722.

Clark KA, McElhinny AS, Beckerle MC, Gregorio CC. 2002. Striated muscle cytoarchitecture: an intricate web of form 
and function. Annu Rev Cell Dev Biol 18: 637-706. doi:10 $.1146 /$ annurev.cellbio.18.012502.105840

Copp AJ. 1995. Death before birth: clues from gene knockouts and mutations. Trends Genet 11: 87-93. doi:10.1016/ S0168-9525(00)89008-3

de Soysa TY, Ranade S, Okawa S, Ravichandran S, Huang Y, Salunga H, Schricker A, del Sol A, Gifford C, Srivastava D. 2019. Single-cell analysis of cardiogenesis reveals basis for organ-level developmental anomalies. Nature 572: 120 124. doi:10.1038/s41586-019-1414-x

Ehler E. 2016. Cardiac cytoarchitecture-why the "hardware" is important for heart function! Biochim Biophys Acta 1863: 1857-1863. doi:10.1016/j.bbamcr.2015.11 .006

Goss CM. 1938. The first contractions of the heart in rat embryos. Anat Rec 70: 505-524. doi:10.1002/ar.1090 700502

Goss C. 1952. Development of the median coordinated ventricle from the lateral hearts in rat embryos with three to six somites. Anat Rec 112: 761-796. doi:10.1002/ar .1091120405

Granados-Riveron JT, Brook JD. 2012. The impact of mechanical forces in heart morphogenesis. Circ Cardiovasc Genet 5: 132-142. doi:10.1161/CIRCGENETICS.111 .961086

Hove JR, Köster RW, Forouhar AS, Acevedo-Bolton G, Fraser SE, Gharib M. 2003. Intracardiac fluid forces are an essential epigenetic factor for embryonic cardiogenesis. Nature 421: 172-177. doi:10.1038/nature01282

Ivanovitch K, Temiño S, Torres M. 2017. Live imaging of heart tube development in mouse reveals alternating phases of cardiac differentiation and morphogenesis. eLife 6: e30668. doi:10.7554/eLife.30668

Kamino K. 1991. Optical approaches to ontogeny of electrical activity and related functional organization during early heart development. Physiol Rev 71: 53-91. doi:10 $.1152 /$ physrev.1991.71.1.53

Karppinen S, Rapila R, Mäkikallio K, Hänninen SL, Rysä J, Vuolteenaho O, Tavi P. 2014. Endothelin-1 signalling controls early embryonic heart rate in vitro and in vivo. Acta Physiol 210: 369-380. doi:10.1111/apha.12194

Karppinen S, Hänninen SL, Rapila R, Tavi P. 2018. Sarcoplasmic reticulum $\mathrm{Ca}^{2+}$-induced $\mathrm{Ca}^{2+}$ release regulates class IIa HDAC localization in mouse embryonic cardiomyocytes. Physiol Rep 6: e13522. doi:10.14814/phy2 .13522

Kaufman MH, Navaratnam V. 1981. Early differentiation of the heart in mouse embryos. J Anat 133: 235-246.

Kobayashi T, Maeda S, Ichise N, Sato T, Iwase T, Seki S, Yamada Y, Tohse N. 2011. The beginning of the calcium transient in rat embryonic heart. J Physiol Sci 61: 141-149. doi:10.1007/s12576-010-0131-x

Koushik SV, Wang J, Rogers R, Moskophidis D, Lambert NA, Creazzo TL, Conway SJ. 2001. Targeted inactivation of the sodium-calcium exchanger $(N c x 1)$ results in the lack of a heartbeat and abnormal myofibrillar organization. FASEB J 15: 1209-1211. doi:10.1096/fj.00-0696fje

Le Garrec JF, Domínguez JN, Desgrange A, Ivanovitch KD, Raphaël E, Bangham JA, Torres M, Coen E, Mohun T), Meilhac SM. 2017. A predictive model of asymmetric morphogenesis from $3 \mathrm{D}$ reconstructions of mouse heart looping dynamics. eLife 6: e28951. doi:10.7554/eLife .28951.

Liang H, Halbach M, Hannes T, Fleischmann BK, Tang M, Schunkert H, Hescheler J, Reppel M. 2010. Electrophysiological basis of the first heart beats. Cell Physiol Biochem 25: 561-570. doi:10.1159/000315075

Linask KK, Han MD, Artman M, Ludwig CA. 2001. Sodiumcalcium exchanger (NCX-1) and calcium modulation: NCX protein expression patterns and regulation of early heart development. Dev Dyn 221: 249-264. doi:10.1002/ dvdy.1131

Lucitti JL, Jones EAV, Huang C, Chen J, Fraser SE, Dickinson ME. 2007. Vascular remodeling of the mouse yolk sac requires hemodynamic force. Development 134: 33173326. doi:10.1242/dev.02883

Lux C, Yoshimoto M, McGrath K, Conway S, Palis J, Yoder M. 2007. All primitive and definitive hematopoietic progenitor cells emerging before E10 in the mouse embryo are products of the yolk sac. Blood 111: 3435-3438. doi:10 .1182/blood-2007-08-107086

McDole K, Guignard L, Amat F, Berger A, Malandain G, Royer LA, Turaga SC, Branson K, Keller PJ. 2018. In toto imaging and reconstruction of post-implantation mouse development at the single-cell level. Cell 175: 859-876.e33. doi:10.1016/j.cell.2018.09.031

Meilhac SM, Buckingham ME. 2018. The deployment of cell lineages that form the mammalian heart. Nat Rev Cardiol 15: 705-724. doi:10.1038/s41569-018-0086-9

Mercola M, Ruiz-lozano P, Schneider MD. 2011. Cardiac muscle regeneration: lessons from development. Genes Dev 25: 299-309. doi:10.1101/gad.2018411

Méry A, Aimond F, Ménard C, Mikoshiba K, Michalak M, Pucéat M. 2005. Initiation of embryonic cardiac pacemaker activity by inositol 1,4,5-trisphosphate-dependent calcium signaling. Mol Biol Cell 16: 2414-2423. doi:10 .1091/mbc.e04-10-0883

Mesaeli N, Nakamura K, Zvaritch E, Dickie P, Dziak E, Krause KH, Opas M, MacLennan DH, Michalak M. 1999. Calreticulin is essential for cardiac development. J Cell Biol 144: 857-868. doi:10.1083/jcb.144.5.857

Metzger JM, Westfall MV. 2004. Covalent and noncovalent modification of thin filament action: the essential role of troponin in cardiac muscle regulation. Circ Res 94: 146158. doi:10.1161/01.RES.0000110083.17024.60

Miyasaka KY, Kida YS, Banjo T, Ueki Y, Nagayama K, Matsumoto T, Sato M, Ogura T. 2011. Heartbeat regulates cardiogenesis by suppressing retinoic acid signaling via expression of miR-143. Mech Dev 128: 18-28. doi:10 .1016/j.mod.2010.09.002

Molkentin JD. 2006. Dichotomy of $\mathrm{Ca}^{2+}$ in the heart: contraction versus intracellular signaling. J Clin Invest 116: 623-626. doi:10.1172/JCI27824

Mummery CL, Zhang J, Ng ES, Elliott DA, Elefanty AG, Kamp TJ. 2012. Differentiation of human embryonic stem cells and induced pluripotent stem cells to cardiomyocytes: a methods overview. Circ Res 111: 344-358. doi:10.1161/CIRCRESAHA.110.227512

Nakanishi T, Seguchi M, Takao A. 1988. Development of the myocardial contractile system. Experientia 44: 936-944. doi:10.1007/BF01939887 
R.C.V. Tyser and S. Srinivas

Navaratnam V, Kaufman MH, Skepper JN, Barton S, Guttridge KM. 1986. Differentiation of the myocardial rudiment of mouse embryos: an ultrastructural study including freeze-fracture replication. J Anat 146: 65-85.

Nishii K, Shibata Y. 2006. Mode and determination of the initial contraction stage in the mouse embryo heart. Anat Embryol (Berl) 211: 95-100. doi:10.1007/s00429-0050065-X

Nishii K, Morimoto S, Minakami R, Miyano Y, Hashizume K, Ohta M, Zhan DY, Lu QW, Shibata Y. 2008. Targeted disruption of the cardiac troponin $\mathrm{T}$ gene causes sarcomere disassembly and defects in heartbeat within the early mouse embryo. Dev Biol 322: 65-73. doi:10.1016/j .ydbio.2008.07.007

North TE, Goessling W, Peeters M, Li P, Ceol C, Lord AM, Weber GJ, Harris J, Cutting CC, Huang P, et al. 2009. Hematopoietic stem cell development is dependent on blood flow. Cell 137: 736-748. doi:10.1016/j.cell.2009.04 .023

Papadatos GA, Wallerstein PMR, Head CEG, Ratcliff R, Brady PA, Benndorf K, Saumarez RC, Trezise AEO, Huang CLH, Vandenberg JI, et al. 2002. Slowed conduction and ventricular tachycardia after targeted disruption of the cardiac sodium channel gene Scn5a. Proc Natl Acad Sci 99: 6210-6215. doi:10.1073/pnas.082121299

Patten BM, Kramer TC. 1933. The initiation of contraction in the embryonic chick heart. Am J Anat 53: 349-375. doi:10.1002/aja.1000530302

Periasamy M, Reed TD, Liu LH, Ji Y, Loukianov E, Paul RJ, Nieman ML, Riddle T, Duffy JJ, Doetschman T, et al. 1999. Impaired cardiac performance in heterozygous mice with a null mutation in the sarco(endo)plasmic reticulum $\mathrm{Ca}^{2+}$-ATPase isoform 2 (SERCA2) gene. J Biol Chem 274: 2556-2562. doi:10.1074/jbc.274.4.2556

Pijuan-Sala B, Griffiths JA, Guibentif C, Hiscock TW, Jawaid W, Calero-Nieto FJ, Mulas C, Ibarra-Soria X, Tyser RCV, Ho DLL, et al. 2019. A single-cell molecular map of mouse gastrulation and early organogenesis. Nature 566: 490-495. doi:10.1038/s41586-019-0933-9

Platzer J, Engel J, Schrott-Fischer A, Stephan K, Bova S, Chen H, Zheng H, Striessnig J. 2000. Congenital deafness and sinoatrial node dysfunction in mice lacking class D L-type $\mathrm{Ca}^{2+}$ channels. Cell 102: 89-97. doi:10.1016/S0092-8674 (00)00013-1

Pucéat M, Jaconi M. 2005. $\mathrm{Ca}^{2+}$ signalling in cardiogenesis. Cell Calcium 38: 383-389. doi:10.1016/j.ceca.2005.06.016

Rapila R, Korhonen T, Tavi P. 2008. Excitation-contraction coupling of the mouse embryonic cardiomyocyte. J Gen Physiol 132: 397-405. doi:10.1085/jgp.200809960
Reppel M, Sasse P, Malan D, Nguemo F, Reuter H, Bloch W, Hescheler J, Fleischmann BK. 2007. Functional expression of the $\mathrm{Na}^{+} / \mathrm{Ca}^{2+}$ exchanger in the embryonic mouse heart. J Mol Cell Cardiol 42: 121-132. doi:10.1016/j.yjmcc .2006 .10 .008

Sabin F. 1920. Studies on the origin of blood-vessels and of red blood-corpuscles as seen in the living blastoderm of chicks during the second day of incubation. Contrib Embryol 9: 213-262.

Sasse P, Zhang J, Cleemann L, Morad M, Hescheler J, Fleischmann BK. 2007. Intracellular $\mathrm{Ca}^{2+}$ oscillations, a potential pacemaking mechanism in early embryonic heart cells. J Gen Physiol 130: 133-144. doi:10.1085/jgp .200609575

Seisenberger C, Specht V, Welling A, Platzer J, Pfeifer A, Kühbandner S, Striessnig J, Klugbauer N, Feil R, Hofmann F. 2000. Functional embryonic cardiomyocytes after disruption of the L-type $\alpha_{1 \mathrm{C}}\left(\mathrm{Ca}_{v} 1.2\right)$ calcium channel gene in the mouse. J Biol Chem 275: 39193-39199. doi:10 $.1074 /$ jbc.M006467200

Stieber J, Herrmann S, Feil S, Löster J, Feil R, Biel M, Hofmann F, Ludwig A. 2003. The hyperpolarizationactivated channel HCN4 is required for the generation of pacemaker action potentials in the embryonic heart. Proc Natl Acad Sci 100: 15235-15240. doi:10.1073/pnas 2434235100

Takeshima H, Komazaki S, Hirose K, Nishi M, Noda T, Iino M. 1998. Embryonic lethality and abnormal cardiac myocytes in mice lacking ryanodine receptor type 2. $E M B O J$ 17: 3309-3316. doi:10.1093/emboj/17.12.3309

Triedman JK, Newburger JW. 2016. Trends in congenital heart disease. Circulation 133: 2716-2733. doi:10.1161/ CIRCULATIONAHA.116.023544

Tyser RCV, Miranda AMA, Chen CM, Davidson SM, Srinivas S, Riley PR. 2016. Calcium handling precedes cardiac differentiation to initiate the first heartbeat. eLife 5: e17113. doi:10.7554/eLife.17113

Viatchenko-Karpinski S, Fleischmann BK, Liu Q, Sauer H, Gryshchenko O, Ji GJ, Hescheler J. 2002. Intracellular $\mathrm{Ca}^{2+}$ oscillations drive spontaneous contractions in cardiomyocytes during early development. Proc Natl Acad Sci 96: 8259-8264. doi:10.1073/pnas.96.14.8259

Wakimoto K, Kobayashi K, Kuro-o M, Yao A, Iwamoto T, Yanaka N, Kita S, Nishida A, Azuma S, Toyoda Y, et al. 2000. Targeted disruption of $\mathrm{Na}^{+} / \mathrm{Ca}^{2+}$ exchanger gene leads to cardiomyocyte apoptosis and defects in heartbeat. J Biol Chem 275: 36991-36998. doi:10.1074/jbc .M004035200 


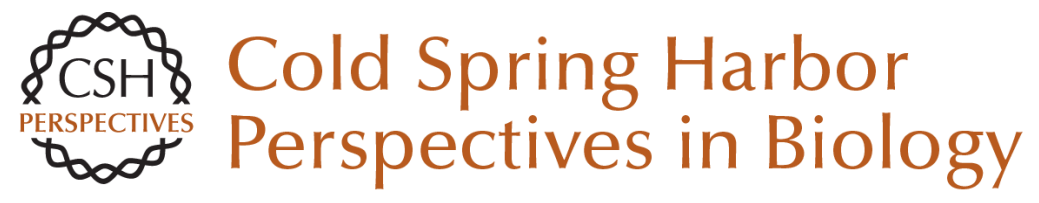

\section{The First Heartbeat--Origin of Cardiac Contractile Activity}

Richard C.V. Tyser and Shankar Srinivas

Cold Spring Harb Perspect Biol 2020; doi: 10.1101/cshperspect.a037135 originally published online November 25, 2019

\section{Subject Collection Heart Development and Disease}

Epicardium in Heart Development Yingxi Cao, Sierra Duca and Jingli Cao

Cardiac Neural Crest Hiroyuki Yamagishi

The Endocardium and Heart Valves Bailey Dye and Joy Lincoln

Long Noncoding RNAs in Cardiac Development Michael Alexanian and Samir Ounzain

Genetic Basis of Human Congenital Heart Disease Shannon N. Nees and Wendy K. Chung

Cardiopharyngeal Progenitor Specification:

Multiple Roads to the Heart and Head Muscles Benjamin Swedlund and Fabienne Lescroart

Genetic and Epigenetic Control of Heart Development

Brynn N. Akerberg and William T. Pu

Formation and Growth of Cardiac Lymphatics during Embryonic Development, Heart Regeneration, and Disease

Dana Gancz, Gal Perlmoter and Karina Yaniv
In Vivo and In Vitro Genetic Models of Congenital Heart Disease Uddalak Majumdar, Jun Yasuhara and Vidu Garg

Development of the Cardiac Conduction System Samadrita Bhattacharyya and Nikhil V. Munshi

3D Anatomy of the Developing Heart:

Understanding Ventricular Septation

Timothy J. Mohun and Robert H. Anderson

Cardiac Morphogenesis: Specification of the

Four-Chambered Heart

Vincent Christoffels and Bjarke Jensen

The Chicken as a Model Organism to Study Heart

Development

Johannes G. Wittig and Andrea Münsterberg

The First Heartbeat--Origin of Cardiac Contractile

Activity

Richard C.V. Tyser and Shankar Srinivas

Xenopus: Experimental Access to Cardiovascular

Development, Regeneration Discovery, and

Cardiovascular Heart-Defect Modeling Stefan Hoppler and Frank L. Conlon

Reptiles as a Model System to Study Heart

Development

Bjarke Jensen and Vincent M. Christoffels

For additional articles in this collection, see http://cshperspectives.cshlp.org/cgi/collection/

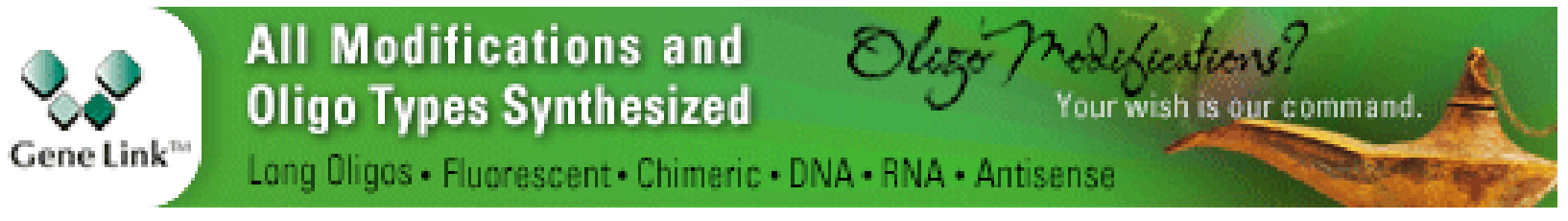

Copyright @ 2020 Cold Spring Harbor Laboratory Press; all rights reserved 